\title{
Securing aesthetic outcomes for composite grafts to alar margin and columellar defects: A long term experience
}

\author{
Rajeev B. Ahuja, Rajat Gupta, Pallab Chatterjee, Prabhat Shrivastava
}

Department of Burns and Plastic Surgery, Lok Nayak Hospital and Associated Maulana Azad Medical College, New Delhi, India

Address for correspondence: Dr. Rajeev B. Ahuja, Department of Burns and Plastic Surgery, Lok Nayak Hospital and Associated Maulana Azad Medical College, New Delhi - 110 002, India. E-mail: rbahuja@gmail.com

\section{ABSTRACT}

Introduction: Composite grafts for nasal reconstruction have been around for over a century but the opinion on its virtues and failings keeps vacillating with a huge difference on the safe size of the graft for transfer. Alar margin and columellar defects are more distinct than dorsal nasal defects in greater difficulty in ensuring a good aesthetic outcome. We report our series of 19 consecutive patients in whom a composite graft was used to reconstruct a defect of alar margin (8 patients), alar base (7 patients) or columella (4 patients). Patients and Methods: Patient ages ranged from 3-35 years with 5 males and 14 females. The grafts to alar margin and base ranged 0.6-1 cm in width, while grafts to columella were $0.7-1.2 \mathrm{~cm}$. The maximum dimension of the graft in this series was $0.9 \mathrm{~mm} \times 10 \mathrm{~mm}$. Composite grafts were sculpted to be two layered (skin + cartilage), three layered wedges (skin + cartilage + skin) or their combination (two layered in a portion and three layered in another portion). All grafts were cooled in postoperative period for three days by applying an indigenous ice pack of surgical glove. The follow up ranged from 3-9 months with an average of 4.5 months. Results: All of our 19 composite grafts survived completely but they all shrank by a small percentage of their bulk. Eleven patients rated the outcome between 90-95\% improvement. We noticed that composite grafts tended to show varied pigmentation in our patients, akin to split skin grafts. Conclusion: In our opinion, most critical to graft survival is its size and the ratio of the marginal raw area to the graft bulk. We recommend that graft width should not exceed $1 \mathrm{~cm}$ to ensure complete survival even though larger sized grafts have been reported to survive. We recommend cooling of the graft and justify it on the analogy of "warm ischemia time' for a replantation, especially in warmer climes like ours in India. We have outlined several considerations in the technique, with an analysis of differing opinions that should facilitate a surgeon in making an informed choice.

\section{KEY WORDS}

Alar defect; columellar defect; composite grafts; nose defects

\begin{tabular}{|l|l|}
\hline \multicolumn{2}{|c|}{ Access this article online } \\
\hline Quick Response Code: & Website: \\
\hline & www.ijps.org \\
\cline { 2 - 2 } & Dol: \\
\hline
\end{tabular}

\section{INTRODUCTION}

We first description of composite grafts for nasal reconstruction dates back to Konig in 1902.11 Despite a modern history spanning over a century, composite grafts continue to be an enigma for many surgeons. Pessimism expressed through publications by 
Joseph $^{[2]}$ and Limberg ${ }^{[3]}$ over high failure rates, discouraged the surgeons of that time, till other successful reports ${ }^{[4-10]}$ established the procedure. Since then there have been more articles describing enhanced graft survival by cooling, ${ }^{[1]}$ on bettering the aesthetic outcomes by appropriating the donor site of the composite graft, ${ }^{[12,13]}$ and on management of the ear as a donor site. ${ }^{[14,15]}$ In an era where a small piece of vascularised tissue can be made available for similar reconstruction, ${ }^{[16]}$ the charm of simplicity of a composite graft lacks conviction if survival and aesthetic outcomes are not ensured. Majority of articles don't directly report a success rate, but mention means and modifications to enhance it or limit donor site morbidity. Some have alluded to bettering the results by donor site selection and graft size restrictions. Within nasal defects appropriate for reconstruction by a composite graft, the subset of alar margin and columellar defects is more distinct in greater difficulty in restoring blood supply and ensuring a good aesthetic outcome.

A good aesthetic result with a composite graft can only be hoped for if vascular survival is unquestionable. Through our fairly large experience with composite grafts we discuss the methods and modifications which we have employed to enhance our practice with them.

\section{PATIENTS AND METHODS}

This report is a series of 19 consecutive patients in whom a composite graft was used to reconstruct a defect of alar margin, alar base or columella. Composite grafts to the dorsum of the nose, not involving a free margin, have been excluded from this report. Aetiology of the defects has been congenital ( 2 patients), post-traumatic (10 patients) and post-burn (7 patients). All surgeries were performed by a single surgeon in last 15 years, under general anaesthesia. Their ages have ranged from 3 years to 35 years and there were 5 males and 14 females. None of the patients gave a history of smoking. The grafts to alar margin have ranged $0.6-0.9 \mathrm{~cm}$ in width while grafts to the columella have ranged $0.7-1.2 \mathrm{~cm}$. Table 1 summarizes the nasal defects and the auricular donor site harvested for composite grafts.

\section{Surgical technique}

The defect at the recipient site is freshened and anatomical repositioning of the margin done, as may be necessary. Whereas, no template ${ }^{[4]}$ has ever been necessary to harvest the graft for these areas, slightly larger graft is harvested than the defect. The choice of donor site on the ear helix has been most critical. The donor site on the ear is not infiltrated with either lidocaine or adrenaline to facilitate graft harvest. The excess skin harvested in the graft is suitably trimmed after trial placements. Composite grafts have been sculpted to be two layered (skin + cartilage) [Figure 1], three layered wedges (skin + cartilage + skin) [Figure 2] or their combination (two layered in a portion and three layered in another portion) [Figure 3]. Two layered grafts were exclusively used for columellar defects. In most of the alar defects it is possible to elevate a hinge flap from the defect margin to fit in a bespoke 'combination' graft, with the three layers component reconstructing the alar margin, and the two layered flange lying on the hinge flap to build up the superior portion. The use of 1:2,00,000 dilution adrenaline infiltration is restricted to elevation of the hinge flap alone, and the bleeding is controlled by pressure or very sparing use of bipolar cautery. Grafts are sutured externally with 5 ' 0 '/6 ' 0 ' nylon or prolene. The nasal lining is sutured with 6 ' 0 ' vicryl. Donor sites have similarly been closed with direct approximation of cartilage using 6 ' 0 ' vicryl, and 5 ' 0 ' nylon or prolene sutures for the skin. The maximum dimension of the graft in this series has been $0.9 \mathrm{~mm} \times 10 \mathrm{~mm}$.

Table 1: Nasal defects and the auricular donor site harvested for composite grafts

\begin{tabular}{lcl}
\hline Defect location & Patients & Donor site \\
\hline Alar base & 8 & Superior helical margin \\
Alar margin & 3 & Superio-lateral helical rim \\
& 4 & Body of helix \\
Columella & 2 & Lower helical margin \\
& 2 & Upper lobule \\
Total & 19 & \\
\hline
\end{tabular}

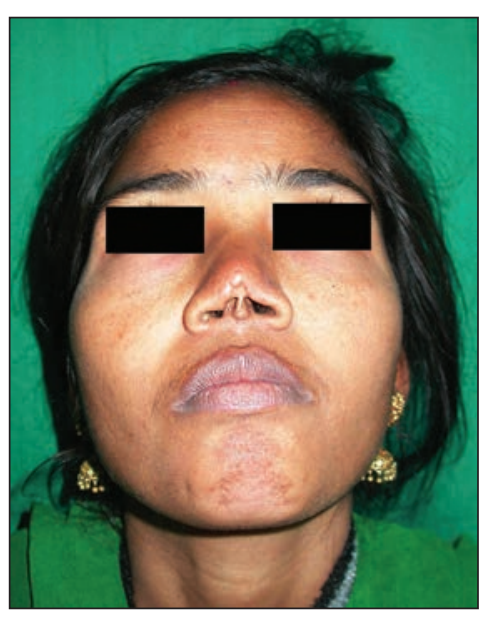

Figure 1a: A 35-year-old lady with a $12 \mathrm{~mm} \times 6 \mathrm{~mm}$ traumatic loss of superficial columella 


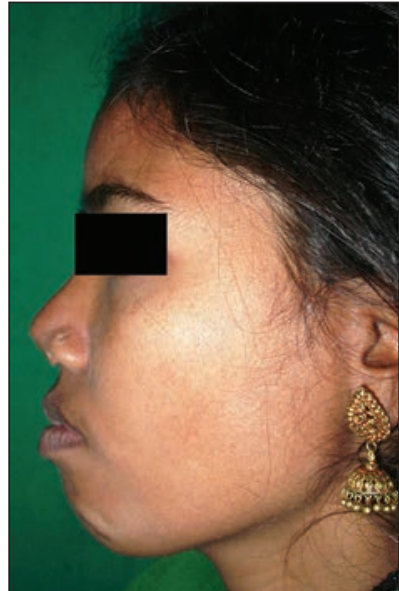

Figure 1b: Profile view showing loss of columellar projection

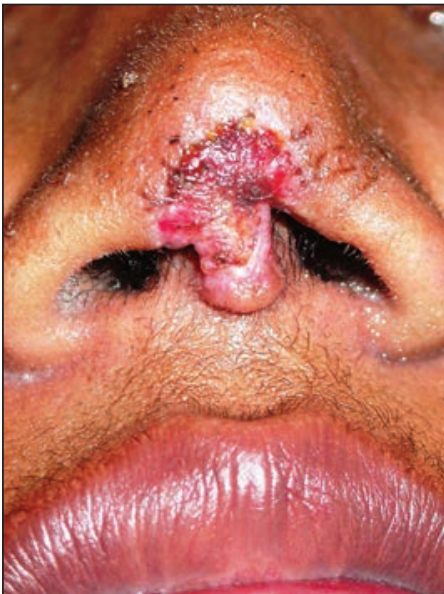

Figure 1d: A two-dimensional composite graft was placed on the defect. Result at $12^{\text {th }}$ postoperative day shows extensive epidermolysis

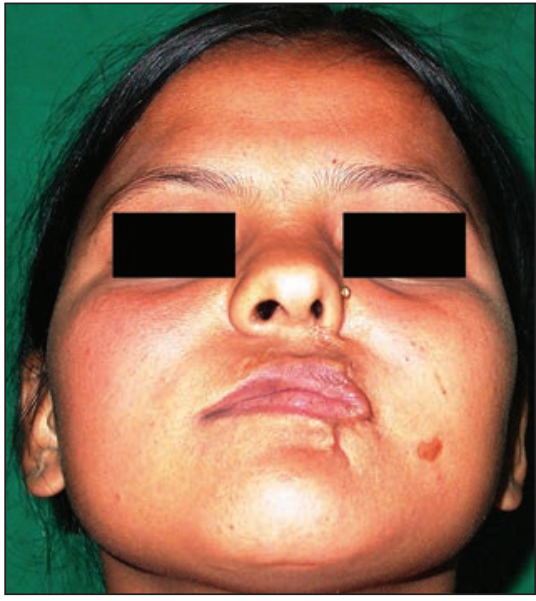

Figure 2a: A 19-year-old girl with constricted left nostril following acid burns. Right alar base and sill were reconstructed by a $10 \mathrm{~mm}$ wide wedge graft harvested from superior helical rim after recreating the defect. The donor defect was closed primarily

The nasal cavity is packed with paraffin gauze. The recipient site is smeared with an antibacterial ointment and left open for inspection. Immediately following surgery, and up to

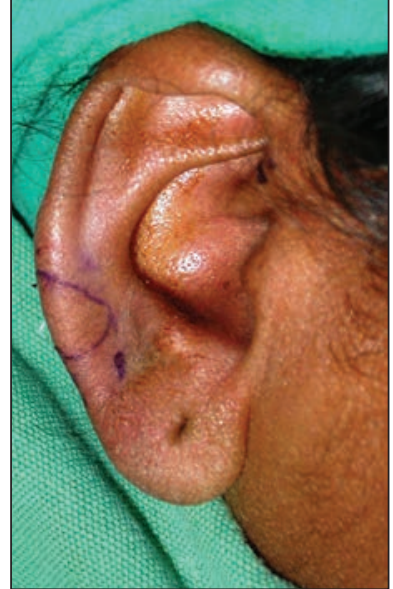

Figure 1c: An appropriate size composite graft was harvested from the lower helical margin and the donor defect closed primarily

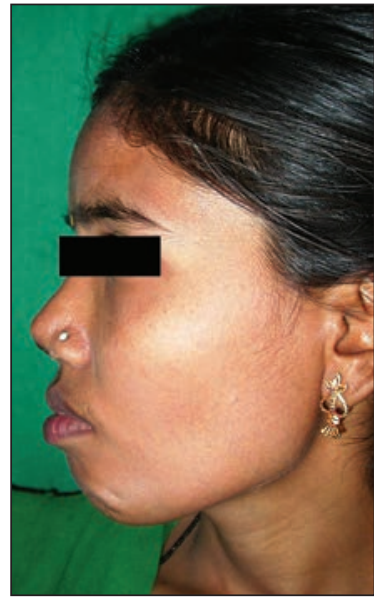

Figure 1e: Profile view of the patient at 6 months follow-up showing adequate restoration of columellar projection, albeit with hyperpigmentation

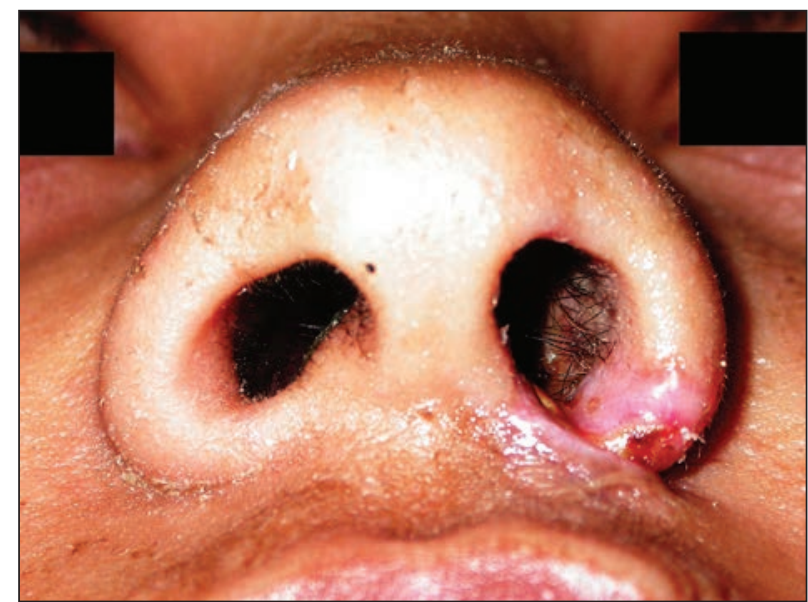

Figure $\mathbf{2 b}$ : A close up basal view of the nostrils at $15^{\text {th }}$ postoperative day. There is complete take of the graft but it is hypopigmented with a small area of epidermolysis still persisting

3 days postoperatively, the grafts are cooled, in situ, with direct application of ice packs. Ice packs are indigenously prepared by filling a surgical glove with crushed ice and 


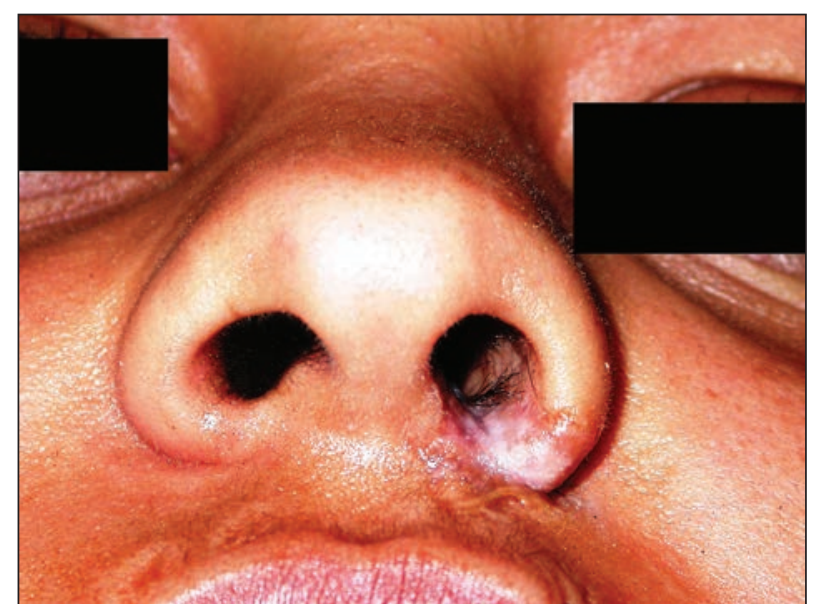

Figure 2c: Close up basal view of the nostrils at 4 months follow-up showing healing of the small ulceration and gradual return of pigmentation

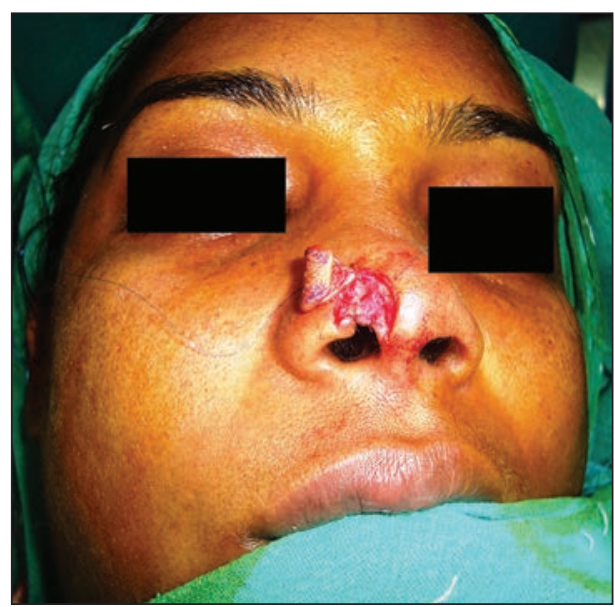

Figure 3b: A hinge flap was elevated from the recipient defect margin and the 'combination' graft was fixed into the defect

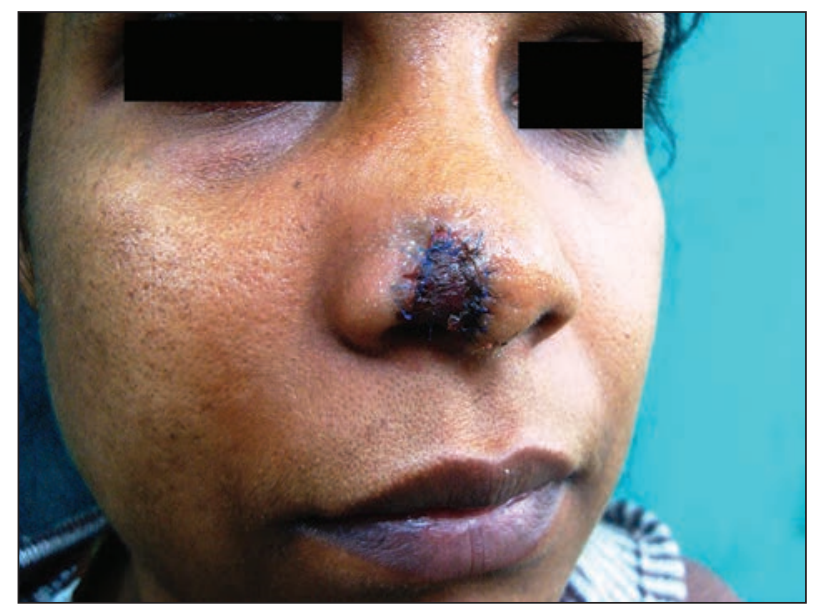

Figure 3d: Venous congestion of the graft on the $8^{\text {th }}$ postoperative day

using the 'glove finger' as the cooling tip on the graft. This is executed by the patient or his/her attendant with some help from nurses. No steroid creams or injections are ever prescribed. The follow-up has ranged from 3 to 10

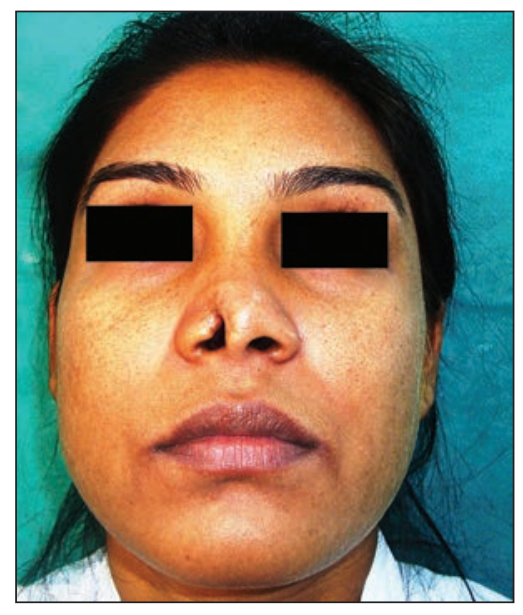

Figure 3a: A 24-year-old girl with a $10 \mathrm{~mm}$ wide defect in right alar margin resulting from trauma. A composite graft of same size was harvested from right ear's superio-lateral helical rim. Donor defect was closed primarily

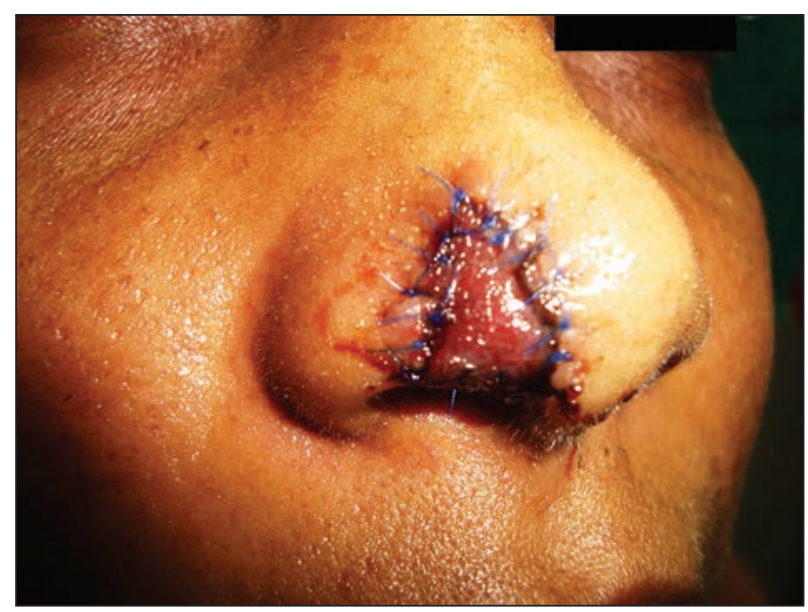

Figure 3c: Pinkish discoloration of the graft on $5^{\text {th }}$ postoperative day

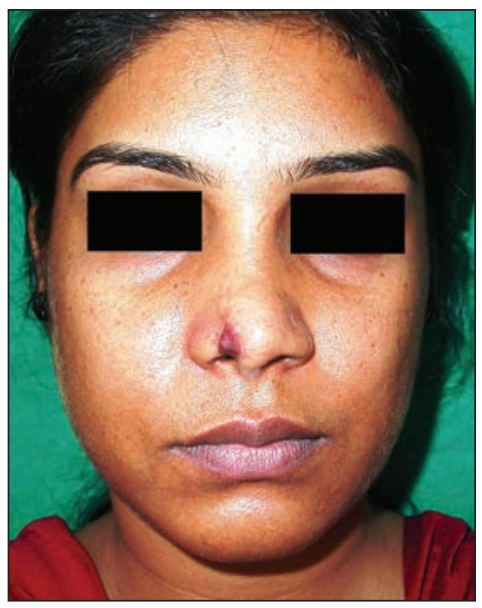

Figure 3e: Result at 3 months follow-up shows the graft has survived completely with some hyperpigmentation and graft shrinkage

months with an average of 4.5 months. During follow-up, if hyperpigmentation is noticed, the patient is advised to apply a hydroquinone cream locally, twice daily. 


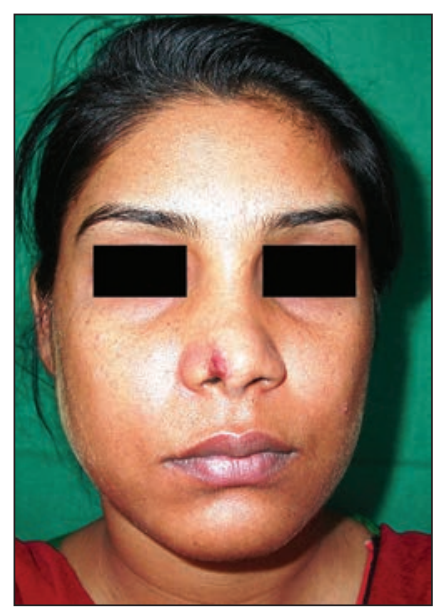

Figure 3f: Result at 5 months showing mild improvement in hyperpigmentation

\section{RESULTS}

All 19 composite grafts survived completely, but they all shrank by a small percentage of their bulk. The temporal sequence of composite graft survival and shrinkage is succinctly captured in Figure 3c-f. The patients or their parents (in case of small children) were asked to rate the aesthetic outcomes as a percentage of perceived improvement. Eleven patients rated the outcome between $90 \%$ and $95 \%$ improvements. Two patients rated it between $80 \%$ and $90 \%$ improvement and the remaining six patients placed it between $70 \%$ and $80 \%$. In spite of complete graft survival, the quality of aesthetic outcome was rated below $90 \%$ in eight patients. In three patients, the below par aesthetic outcome could be attributed to loss of bulk, in another three patients there was either hypo or hyperpigmentation of the graft, and in two patients the contour was inadequate for proper match at recipient site. Three results, representing differing aetiologies and recipient sites, can be reviewed from Figures 1-3. The average hospital stay for these patients ranged from 10 to 12 days.

\section{DISCUSSION}

Experience with composite grafts is not easy to come by because the potential nasal defects appropriate for such reconstructions are uncommon even in busy plastic surgery practices, and having not witnessed it in formative years due to infrequent usage, the procedure is often considered unreliable. Unfortunately, despite the huge advantage of reconstruction with a composite graft it has been viewed with much scepticism because of fear of failure.

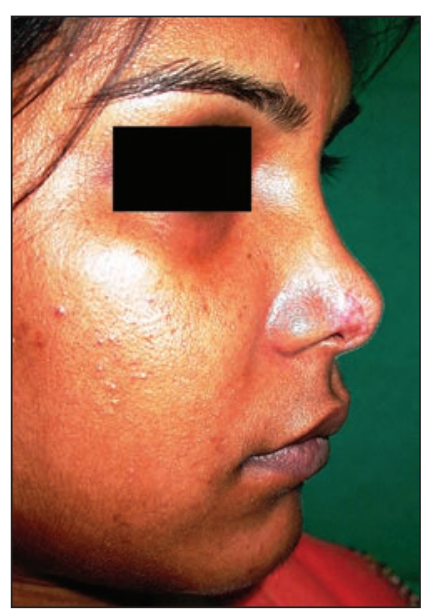

Figure 3g: Result at 10 months showing considerable improvement in hyperpigmentation by application of a hydroquinone cream locally

Composite grafts for reconstruction of small defects of the nose are a great tool in the armamentarium to provide single staged reconstructions. The quality of reconstruction that a composite graft can bring to such reconstructions is unparalleled and cannot be surpassed by local/regional flaps, which tend to bring in excess bulk that compromises aesthetic result. Small flaps appropriate for such reconstructions are also not easy to locate or design. A seemingly simple procedure, composite grafting still requires exquisite planning and execution to ensure complete survival, and an aesthetic result surpassing that from a local flap. Although, composite grafts from the ear provide textured matched tissue for nose reconstruction they tend to show the varied pigmentation in dark skinned individuals, like Indians, just as split skin grafts. This observation has never been reported before. Nevertheless, their value in restoring a free alar margin of nose, soft triangle or columella in suitable patients can only be appreciated if witnessed.

\section{Size of the graft and restoring graft vascularity}

In our opinion, most critical to graft survival is its size and the ratio of the marginal raw area to the graft bulk. Whereas some authors, including us, have strongly reported that a graft size exceeding $10 \mathrm{~mm}$ is not suitable for reconstruction because of limited blood flow, ${ }^{[4,17-19]}$ there are those who report high success with graft size between 10 and $20 \mathrm{~mm}^{[20]}$ or even up to $25 \mathrm{~mm} \cdot{ }^{[15,21]}$ Grafts exceeding $10 \mathrm{~mm}$ may well survive, but the success rate is about $65 \%$ for defects approaching $15 \mathrm{~mm}$ and $<50 \%$ for grafts exceeding $15 \mathrm{~mm} .{ }^{[18]}$

We feel a distinction could be made between the permissible sizesoftwo-dimensional, three-dimensional and 'combination' 
grafts. Our experience, and that of others who recommend grafts $<10 \mathrm{~mm}$, is more in terms of three-dimensional wedge grafts, but we concede that two-dimensional or 'combination' grafts could be wider. In a marginally larger composite graft, we are always careful to convert it into a 'combination' graft to augment revascularization. It is known that a composite graft revascularization mainly takes place at the margin, ${ }^{[17]}$ with much less contribution from the graft base, and therefore, in our opinion and that expressed by Cheon and Park, ${ }^{[22]}$ the farthermost portion of the graft should be no $>0.5 \mathrm{~cm}$ from the revascularising margin. However, in Ruch's ${ }^{[23]}$ and McLaughlin's opinion ${ }^{[9]}$ this distance could be $1 \mathrm{~cm}$. This is mentioned here to suggest the possibility of reconstructing an alar marginal defect which exceeds $10-15 \mathrm{~mm}$ width, but is less in height. Indeed, in a series of eight cases, Pilanci et al. ${ }^{[21]}$ reported alar margin reconstruction with composite grafts of sizes ranging $11 \mathrm{~mm} \times 24 \mathrm{~mm}$, using turnover hinge flaps to augment blood supply. The 11 $\mathrm{mm}$ height in their cases exceeds an accepted safe limit, but they seem to have obtained complete success using turnover flaps with 'combination' grafts.

Cooling of composite grafts was introduced by Conley and Vonfraenkel to decrease metabolic demands and increase the chances of success. ${ }^{[1]}$ Even though, there is no strong evidence to support cooling as a practice to enhance chances of graft survival, majority of authors have advocated its use. ${ }^{[9,15,17,24]}$ At the same time, quite surprisingly, three series reporting high success with large sized composite grafts did not resort to cooling. ${ }^{[20,21,25]}$ We feel this practice could be justified on the analogy of 'warm ischemia time' for a replantation, and is recommended by us if ambient temperatures are high, as is often the case in our country. Cooling has been considered impractical over a period of 14 days $^{[25]}$ as was originally recommended. ${ }^{[1]}$ We cool our grafts for just 3 days, till revascularisation begins to establish, and the gloved finger device makes the process effective, and less cumbersome or messy. Even though, McLaughlin ${ }^{[9]}$ has beautifully outlined the sequence of composite graft revascularization we have noticed a slight delay in reaching these milestones in our patients where first sign of pinkishness appears on $3^{\text {rd }}$ day and the graft colour turns blue by $5-6^{\text {th }}$ day [Figure $\left.3 c-f\right]$. This may be due to darker skin of our patients making it difficult to appreciate the subtle colour changes of initial 2-3 days.

Another debatable issue for which no high-quality evidence is available is the use of adrenaline infiltration to harvest the graft. We have not found it necessary to inject adrenaline to harvest a small graft from the ear, and this view is shared by Son et al. ${ }^{[20]}$ who infiltrate lidocaine alone at donor site. However, some other authors prefer to inject a combination of lidocaine and adrenaline to facilitate graft harvest. ${ }^{[15,21,24]}$ It is possible that they indulge in this practice when advancement techniques become necessary to close a donor defect following harvest of a large graft. We feel infiltration leads to unnecessary disruption of the skin-perichondrial attachment at its margins.

Factors favourable to maximise the outcomes from composite grafts are summarized in Table 2.

\section{Analysing aesthetic outcomes}

One of the most critical aspects of decision making is the choice of the donor site on the helical margin. We have preferred superior helix for alar base defects; superiolateral helical margin or body of helix for alar margin defects and lower helical margin or upper lobule for columellar defects but the choice is dictated by sighting a good match on any portion of the helix. Singh and Bartlett have shown a satisfactory result from primary donor site closure without helical rotation, advancement flap or skin graft for defects up to $15 \mathrm{~mm} .{ }^{[14]}$ The root of the helix has also been preferred as a donor site in earlier case reports but the closure of the donor site involves advancement flaps. ${ }^{[12,13]}$ Recently, Zilinsky et al. reported their experience with a graft from crus helix in nasal alar reconstruction. ${ }^{[24]}$

We have noticed that composite grafts shrink in the postoperative period and this is most noticeable in the $1^{\text {st }}$ month. We hypothesise this result from central ischemic fat necrosis in subcutaneous layer [Figure 3]. Some of this shrinkage, leading to an inferior outcome, may be a result of the warmer ambient temperatures increasing the metabolic demands. There are again ambivalent views on this phenomenon as some authors believe minimal contraction occurs routinely but requires no compensation ${ }^{[15,20,22]}$ and some compensate it by providing a little extra bulk to the graft. At the same time, majority

Table 2: Favourable factors to maximise outcomes in composite grafts

No infiltration while harvesting from auricle

Limit the size of graft to $1 \mathrm{~cm}$

Increase the contact surface of the graft with recipient bed

Use a two-dimensional flange to a wedge graft

Minimal use of cautery on recipient site

Accurate suturing of the graft using fine sutures

No post-operative occlusive dressings

Post-operative cooling of the graft 
of authors have omitted to comment on this phenomenon while a report even refutes graft contraction. ${ }^{[21]}$

We have also noticed that composite grafts may hypo [Figure 2] or hyper-pigment [Figures 1-3] in our population. This colour change has never been reported earlier as we have not come across any report on composite grafting from a country with dark skin population. Grafts which hypopigmenttends to recover their colour over a period of months. Hyper-pigmentation is seen when ischemic epidermolysis takes place in a graft with reepithelialisation. This colour change is quite resistant to significant improvement and the phenomenon is quite akin to skin grafts getting pigmented in dark skinned individuals. However, use of a hydroquinone based cream over 3-4 months helps in lowering the extent of pigmentation [Figure $3 \mathrm{~g}$ ].

\section{CONCLUSION}

As nose occupies the prima donna location on the face it should preferably be reconstructed in a single stage with least tell-tale marks, blobs of tissue or colour blemishes. For small defects of the alar base, alar margin and columella, a composite graft from the ear offers a reliable and the best possible result. We have outlined several considerations in the technique, with an analysis of differing opinions, to facilitate a surgeon in making an informed choice. Whereas our experience suggests grafts up to $1 \mathrm{~cm}$ size should survive routinely the same cannot be expected from larger grafts, as can be interpreted from articles quoted above. In any case a learning curve is envisioned in ensuring higher success with this procedure which should be an essential tool in the armamentarium. Choice of the donor site on the ear is critical to a better aesthetic outcome.

\section{REFERENCES}

1. Konig F. ZurDeckung von Defekten der Nasenfugel. Klin Wochenschr 1902;7:137-8. Quoted by Symonds FC, Crikelair GF. Auricular composite grafts in nasal reconstruction: A report of 36 cases. Plast Reconstr Surg 1966;37:433-7.

2. Joseph J. Nasenplastik. Leipzig: Curt Kabitzsch; 1931. p. 383. Quoted by McLaughlin CR. Composite ear grafts and their blood supply. Br J Plast Surg 1954;7:274-8.

3. Limberg AA. Rhinoplasty using free transplant from concha. Sov Khir 1935;9:70. Quoted by Symonds FC, Crikelair GF. Auricular composite grafts in nasal reconstruction: A report of 36 cases. Plast Reconstr Surg 1966;37:433-7.

4. Brown JB, Cannon B. Composite free grafts of two surfaces of skin and cartilage from the Ear. Ann Surg 1946;124:1101-7.

5. Brown JB, Cannon B. Further reports on the use of composite free grafts of skin and cartilage from the ear. Plast Reconstr Surg (1946) 1946;1:130-4.
6. Szlazak J. Repair of nasal defects with free auricular grafts; report of four cases. Br J Plast Surg 1948;1:176-80.

7. Converse JM. Reconstruction of the naso-labial area by composite graft from the concha. Plast Reconstr Surg 1950;5:247-51.

8. Farina R. Loss of substance from the nasal alae and tip: Repairing with free chondro-cutaneous graft from the auricular pavilion. Plast Reconstruct Surg 1952;9:52-4.

9. McLaughlin CR. Composite ear grafts and their blood supply. $\mathrm{Br}$ J Plast Surg 1954;7:274-8.

10. Meade RJ. Composite ear grafts for construction of columella; composite ear grafts for the correction of nasal deformities associated with cleft lip and other congenital and post-traumatic deficiencies of the columella. Plast Reconstr Surg Transplant Bull 1959;23:134-47.

11. Conley JJ, Vonfraenkel PH. The principle of cooling as applied to the composite graft in the nose. Plast Reconstr Surg (1946) 1956;17:444-51.

12. Argamaso RV. An ideal donor site for the auricular composite graft. Br J Plast Surg 1975;28:219-21.

13. Peach $\mathrm{AH}$, Stretch JR. Improved selection and management of the auricular composite graft donor site. $\mathrm{Br} \mathrm{J}$ Plast Surg 2004;57:797-9.

14. Singh DJ, Bartlett SP. Aesthetic management of the ear as a donor site. Plast Reconstr Surg 2007;120:899-908.

15. Haug MD, Rieger UM, Witt P, Gubisch W. Managing the ear as a donor site for composite graft in nasal reconstruction: Update on technical refinements and donor site morbidity in 110 cases. Ann Plast Surg 2009;63:171-5.

16. Parkhouse N, Evans D. Reconstruction of the ala of the nose using a composite free flap from the pinna. $\mathrm{Br} \mathrm{J}$ Plast Surg 1985;38:306-13.

17. Lehman JA Jr, Garrett WS Jr, Musgrave RH. Earlobe composite grafts for the correction of nasal defects. Plast Reconstr Surg 1971;47:12-6.

18. Haas AF, Glogau RG. A variation of composite grafting for reconstruction of full-thickness nasal alar defects. Arch Dermatol 1994;130:978-80.

19. Burget GC. Aesthetic reconstruction of the nose. In: Mathes SJ, editor. Plastic Surgery. The Head and Neck. $2^{\text {nd }}$ ed. Vol. 2. Philadelphia: Elsevier; 2006. p. 573-648.

20. Son D, Kwak M, Yun S, Yeo H, Kim J, Han K. Large auricular chondrocutaneous composite graft for nasal alar and columellar reconstruction. Arch Plast Surg 2012;39:323-8.

21. Pilanci Ö, Saçak B, Kuvat SV, Sen E, Arslan H, Aygit AC. Use of outsized composite chondrocutaneous grafts in conjunction with dermal turnover flaps for reconstruction of full-thickness alar defects. J Craniofac Surg 2011;22:864-7.

22. Cheon YW, Park BY. Long-term evaluation of elongating columella using conchal composite graft in bilateral secondary cleft lip and nose deformity. Plast Reconstr Surg 2010;126:543-53.

23. Ruch MK. Utilization of composite free grafts. J Int Coll Surg 1958;30:274-5.

24. Zilinsky I, Farber N, Haik J, Weissman O, Israeli H, Winkler E. Nasal ala reconstruction with a crus helix composite graft: $A$ stepladder approach. J Drugs Dermatol 2012;11:376-81.

25. Symonds FC, Crikelair GF. Auricular composite grafts in nasal reconstruction: A report of 36 cases. Plast Reconstr Surg 1966;37:433-7.

How to cite this article: Ahuja RB, Gupta R, Chatterjee P, Shrivastava P. Securing aesthetic outcomes for composite grafts to alar margin and columellar defects: A long term experience. Indian J Plast Surg 2014;47:333-9.

Source of Support: Nil, Conflict of Interest: None declared. 